\title{
ESTUDIO PRELIMINAR DE ESPECIES DE Fusarium PRESENTES EN PIÑA (Ananas comosus) EN COSTA RICA
}

\author{
Mónica Blanco-Meneses ${ }^{1 / *}$, Oscar Castro-Zúniga ${ }^{2}$, Gerardina Umaña-Rojas ${ }^{3}$ \\ Palabras clave: Síntomas; morfología; identificación molecular. \\ Keywords: Symptoms; morphology; molecular identification.
}

Recibido: $15 / 12 / 2020$

Aceptado: 31/05/2021

RESUMEN

Introducción. La piña es el segundo cultivo de mayor importancia en Costa Rica, luego del banano. Se destaca la variedad Golden MD-2 como la de mayor demanda en Estados Unidos y Europa. En el 2019 el área de cultivo fue de 40 000 ha distribuidas en las zonas Norte, Atlántica y Pacífico. Objetivo. Determinar la presencia del patógeno Fusarium guttiforme, e identificar y caracterizar las especies de este género, presentes en el cultivo de piña en Costa Rica. Materiales y métodos. Se recolectaron 215 plantas y 20 frutos de diferentes regiones de Costa Rica en el periodo identificado 2015-2019 para un total de 38175 ha del área sembrada de piña mediante un muestreo dirigido a síntomas relacionados a la "muerte descendente de piña". Para la caracterización morfológica se realizaron observaciones del color del micelio, detalles de estructuras como macro y microconidios, clamidósporas y células conidiógenas en muestras previamente identificadas por medios moleculares. La identificación molecular se realizó a partir de 120 aislamientos con los marcadores moleculares

\footnotetext{
* Autora para correspondencia. Correo electrónico: monica.blancomeneses@ucr.ac.cr

1 Universidad de Costa Rica, Facultad de Ciencias Agroalimentarias, Centro de Investigación en Protección de Cultivos, San José, Costa Rica. (D) 0000-0003-2642-3899.
}

\begin{tabular}{|c|c|}
\hline & $\begin{array}{l}\text { Preliminary study of Fusarium species } \\
\text { neapple crop (Ananas comosus) in Costa } \\
\text { Introduction. Pineapple is the second } \\
\text { important crop in Costa Rica, after banana. } \\
\text { Golden MD-2 variety standing out as the } \\
\text { with the highest demand in the United } \\
\text { and Europe. In } 2019 \text {, the cultivation area } \\
0 \text { o00 ha distributed in the North, Atlantic } \\
\text { acific zones. Objective. To determine the } \\
\text { nce of the pathogen Fusarium guttiforme, } \\
\text { to identify and characterize the present } \\
\text { es of this genus, in the pineapple crop in } \\
\text { Rica. Materials and methods. } 215 \text { plants } \\
20 \text { fruits were collected from different } \\
\text { as between the } 2015-2019 \text { in a total of } 38 \\
\text { a of the pineapple planted area through a } \\
\text { ling directed towards symptoms related } \\
\text { e "descending death of pineapple". For } \\
\text { orphological characterization observations } \\
\text { made of the color of the mycelium, details } \\
\text { uctures such as macro and microconidia, } \\
\text { nydospores and conidiogenic cells in } \\
\text { les previously identified by molecular }\end{array}$ \\
\hline & $\begin{array}{l}\text { Universidad de Costa Rica, Facultad de Ciencias } \\
\text { Agroalimentarias, Centro de Investigación en } \\
\text { Protección de Cultivos, San José, Costa Rica. } \\
\text { (D) 0000-0002-5999-5749. }\end{array}$ \\
\hline 3 & $\begin{array}{l}\text { Universidad de Costa Rica, Facultad de Ciencias } \\
\text { Agroalimentarias, Centro de Investigaciones } \\
\text { Agronómicas, San José, Costa Rica. } \\
\text { (D) 0000-0002-6368-5225. }\end{array}$ \\
\hline
\end{tabular}


ITS y TEF-1 $\alpha$. Resultados. No se detectó $F$. guttiforme en plantaciones de piña en el período comprendido entre 2015-2019. Se identificaron 6 especies, Fusarium ananatum, F. oxysporum, $F$. concolor, $F$. proliferatum, $F$. incarnatum y $F$. solani cuyo número de accesión en el National Center of Biotechnology Information se adjunta en el presente artículo. Las especies $F$. ananatum, $F$. oxysporum y $F$. proliferatum han sido previamente descritas como patogénicas en piña. La presencia de $F$. ananatum en un $95 \%$ de los frutos recolectados, se relacionó con la enfermedad "pudrición del centro del frutículo". $F$. proliferatum es generador de micotoxinas, lo cual podría representar un peligro para la salud animal y humana. Las otras especies no han sido reportadas en piña anteriormente. Conclusión. No se constató la presencia del patógeno $F$. guttiforme, aunque si se identificaron las especies de este género, presentes en el cultivo de piña en Costa Rica. means. Molecular identification was carried out from 120 isolates with the molecular markers ITS and TEF-1 $\alpha$. Results. F. guttiforme was not detected in pineapple plantations in the period between 2015-2019. Six species were identified, Fusarium ananatum, F. oxysporum, $F$. concolor, $F$. proliferatum, $F$. incarnatum and $F$. solani whose accession numbers in the National Center of Biotechnology Information are attached in this article. The species $F$. ananatum, $F$. oxysporum and $F$. proliferatum have been previously described as pathogenic in pineapple. The presence of $F$. ananatum in $95 \%$ of the collected fruit was related with the disease "fruitlet core rot". F. proliferatum is a generator of mycotoxins, which could represent a danger to animal and human health. The other species have not been reported in pineapple before. Conclusion. The presence of the pathogen $F$. guttiforme was not found, although there were identified the species of this genus, present in pineapple cultivation area in Costa Rica.

\section{INTRODUCCIÓN}

La piña es nativa de Sur América y es uno de los cultivos tropicales más importantes en el mercado mundial. En Costa Rica durante el 2020, las exportaciones de banano (US \$ 1 080,8 millones), piña (US \$ 967,2 millones), jarabes y concentrados (US \$ 450,8 millones), café oro (US $\$ 325,6$ millones) y el aceite de palma (US \$ 131,5 millones) representaron el 59,0\% de las ventas de bienes de origen agropecuario (Secretaría Ejecutiva de Planificación Sectorial Agropecuaria 2021). A partir de 1986 toma mayor importancia el cultivo de piña en Costa Rica, inicialmente con la exportación de fruta de la variedad Cayenna Lisa, luego la variedad Champaca, y a partir del 2001 y hasta la actualidad, la variedad comercial de más demanda en Estados Unidos y Europa que es la Golden ripe o MD-2 (CANAPEP 2016). En el 2019 el área de cultivo fue de 40000 hectáreas (ha) (Avendaño 2019), distribuidas en 16 cantones de 3 zonas principalmente. La zona Norte con un área de producción de 22400 ha, el equivalente al $56 \%$ del área cultivada; la zona del Atlántico con 10000 ha que representan el 25\% y la zona del Pacífico que destina 7600 ha, lo cual constituye el 19\%. La producción se encuentra en manos de alrededor de 250 productores de piña, en todo el país (CANAPEP 2016). El ciclo de producción de la piña es anual y desde la siembra de la semilla (plántula), tarda aproximadamente un año para la primera y al menos 10 meses para obtener la segunda cosecha (OIRSA 2011).

El cultivo de piña es altamente susceptible a diferentes plagas, parásitos y patógenos (OIRSA 2011). Entre estas, plagas como las 
cochinillas Dysmicoccus brevipes (Vindas y Blanco 2013), parásitos como el nematodo Pratylenchus spp. (Gamboa 2019), y algunos patógenos como el complejo de virus de la marchitez de la piña (MWP, mealybug wilt of pineapple), Phytophthora nicotianae y P. cinnamomi (Ulate 2018), Fusarium oxysporum (Rojas 2020), y Erwinia carotovora y E. chrysanthemi que son los más comunes (Monge 2018). Una vez que las plantas de piña se ven afectadas por estos organismos es casi imposible obtener la calidad de la fruta exportable que exige el mercado internacional (CANAPEP 2016).

El género Fusarium, pertenece a la familia de los Ascomicetes y comprende los hongos fitopatógenos y saprófitos de mayor dispersión mundial. Este provoca síntomas como la pudrición de raíces (hipoxia o anoxia) o la formación de lesiones en la base de la planta, la marchitez vascular que conduce a una necrosis inicial de los tejidos, incluyendo hojas y brotes, y finalmente la muerte de toda la planta (Singleton y Sainsbury 2006, Retana et al. 2018). Para la clasificación de las especies de Fusarium se utilizan características fenotípicas junto con secuencias genéticas provenientes principalmente de genes como el factor de elongación $1 \alpha$, RPB1 y 2, B-tubulina, y la subunidad de la región pequeña mitocondrial (mtSSU) (Aoki et al. 2014, O'Donnell et al. 1998). Estas regiones génicas han sido de gran utilidad para poder agrupar este género en 23 complejos de especies de Fusarium, que comprenden un total aproximado de 300 especies, de las cuales la mitad no ha sido formalmente descrita (O’Donnell et al. 2009 Summerell 2019).

El primer reporte de una enfermedad relacionada al género Fusarium en piña se dio en Argentina en 1954 y se le asignó el nombre de $F$. subglutinans (Wollenw. \& Reinking), conocida comúnmente como fusariosis y como una de las enfermedades más agresivas. Diez años después, esta misma enfermedad se reportó en Brasil con pérdidas entre el 30\% y el 80\% (de Farias et al. 2010, Jacobs et al. 2010, OIRSA 2011). En 1993 Ventura et al. propusieron una nueva forma especial basada en la especificidad del hospedante y lo llamaron $F$. subglutinans f. sp. ananas. En 1998 el mismo hongo fue nombrado por Nirenberg y O'Donnell como $F$. guttiforme y así se le conoce hasta el momento. Actualmente existen informes de la presencia en Hawaii, el continente asiático, el Caribe, Australia y en América del Sur: Brasil, Argentina, Venezuela y Bolivia (de Farias et al. 2010, Jacobs et al. 2010).

Actualmente, el ataque por $F$. guttiforme, es considerado como la mayor amenaza, debido a la susceptibilidad que presentan las principales variedades comerciales de piña para exportación en particular, el híbrido MD-2. Esta enfermedad produce una pudrición en el centro del fruto, afecta los rebrotes, la corona y la planta en general, además tiene la capacidad de permanecer en los residuos vegetales y lograr sobrevivir en retoños o hijos. Los síntomas van desde marchitez o muerte de los brotes apicales, rompimiento de la filotaxia, hasta atrofia y clorosis, que causan finalmente la muerte de la planta. También afecta el fruto, en el que se puede observar un exudado. Las esporas presentes en los tejidos infectados pueden contaminar y afectar la planta entera, fruta, corona e hijuelos y el patógeno subsiste en los retoños que son infectados al estar adheridos a la planta madre. Los cultivos sin atender son una importante fuente de inóculo. El inóculo una vez establecido se dispersa por viento, lluvia, insectos y material vegetativo (de Farias et al. 2010, Jacobs et al. 2010; OIRSA 2011, Rohrbach et al. 2003).

Otro patógeno de importancia en piña es la especie $F$. ananatum, conocido como el agente causal de la pudrición del centro del frutículo (fruitlet core rot, FCR). Esta es comúnmente conocida como la pudrición negra que afecta a los frutos de piña durante la maduración. Esta enfermedad fue inicialmente reportada en Australia a finales del siglo XIX y su sintomatología fue descrita como "la formación de marcas café oscuro de media a un cuarto de pulgada exactamente debajo de la cáscara y que no alcanzaban la parte central de la fruta" (Barral et al. 2020) y patógenos como Fusarium verticilloides (sin. F. moniliforme) y Penicillum funiculosum fueron 
considerados por mucho tiempo como los agentes causales (Barral et al. 2017). En el 2010, esta sintomatología fue descrita por Jacobs et al. y por $\mathrm{Gu}$ et al. en el 2015 a partir de aislamientos provenientes de Sur África y China, respectivamente. $F$. ananatum presentaba diferencias en características a nivel molecular y morfológicas con respecto a los de F. guttiforme. Jacobs et al. (2010) describen los aislamientos localizados en Sur África como una nueva especie denominada $F$. ananatum, sin embargo, aún no ha sido agrupada oficialmente dentro de los complejos de especies de Fusarium. El patógeno penetra la planta durante los estados de la floración y puede permanecer latente mientras crece el fruto (Barral et al. 2017). Se cree que el patógeno se ve favorecido por temperaturas medias y alta humedad durante el desarrollo del fruto (Fournier et al. 2015) y el daño inicia con una necrosis en las brácteas, conforme pasa el tiempo avanza hacia una pudrición clara y suave, y luego termina con una pudrición oscura y seca, cerca de la cosecha. Es común que los síntomas no sean visibles externamente, lo que hace más difícil el diagnóstico de la enfermedad (Barral et al. 2017).

En Costa Rica durante la primera década del 2000 los productores de piña comenzaron a observar un amarillamiento en la punta de las hojas, el cual en muchos casos fue relacionado a Phytophthora spp. En años posteriores se reportó un incremento en el tamaño y el número de los parches y el "amarillón" (como se le conoce) se ha convertido en una preocupación. La enfermedad se caracteriza por un desecamiento de las hojas de la parte superior (ápice) hacia la base, donde luego se da la muerte descendente de las plantas infectadas. Las plantas presentan un amarillamiento, notable pérdida de vigor en la plantación y severas lesiones a nivel vascular, específicamente en el tallo. Si la enfermedad está avanzada, se presenta un desecamiento total en los primeros 10-18 centímetros de la hoja, luego el resto de las hojas toman un color amarillento similar a los síntomas que en el medio piñero se le llama enfermedad del "virus del wilt". Las plantas que presentan esta enfermedad pueden encontrarse en parches sintomáticos hasta en bloques completos de siembra. En el fruto, a simple vista, no se detecta ningún daño, únicamente la falta de crecimiento si la planta está muy afectada (Agricultores, comunicación personal).

En el 2014, Vásquez y Mata, reportaron la presencia de $F$. oxysporum asociado a varios síntomas descritos anteriormente, sin embargo, no se indica el número de muestras utilizadas para llegar a esta conclusión. Por otra parte, Phytophthora cinnamomi y $P$. nicotianae también han sido descritas por producir este tipo de síntomas (Ulate 2018).

En Costa Rica se le ha dado poca importancia a los problemas que producen las especies de Fusarium en campo y en poscosecha, y se han realizado pocos estudios relacionados a estos patógenos. El objetivo de este trabajo es determinar la presencia o ausencia del patógeno Fusarium guttiforme, e identificar y caracterizar las diferentes especies de este género, presentes en el cultivo de piña en las zonas Norte, Pacífico y Atlántica de Costa Rica.

\section{MATERIALES Y MÉTODOS}

Sitios y recolecta del material. Las plantas de piña se recolectaron en las provincias de Heredia y Alajuela (Región Huetar Norte), Puntarenas (Región Pacífico Central), Limón (Región Huetar Atlántica) y San José (Región Brunca). Un total de 215 plantas sintomáticas completas (raíz y porción aérea) de la variedad MD2, se analizaron en el Laboratorio de Fitopatología del Centro de Investigación en Protección de Cultivos (CIPROC). Un total de 20 frutos se analizaron en el Laboratorio de Tecnología Poscosecha del Centro de Investigaciones Agronómicas (CIA), ambos de la Universidad de Costa Rica, entre 2015 y 2019 (Tabla 1). 
Tabla 1. Plantas sintomáticas de piña recolectadas en diferentes localidades de Costa Rica entre 2015-2019.

\begin{tabular}{|c|c|c|c|c|c|c|}
\hline Región & Provincia & Cantón & Distrito & Localidad & Año recolecta & \# muestras \\
\hline \multirow{16}{*}{ 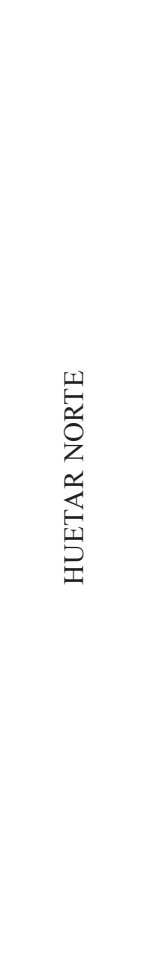 } & \multirow{4}{*}{ Heredia } & \multirow{4}{*}{ Sarapiquí } & \multicolumn{2}{|l|}{ Llano Grande } & 2015-2016 & 5 \\
\hline & & & \multicolumn{2}{|l|}{ Horquetas } & $2015-2016$ & 3 \\
\hline & & & \multicolumn{2}{|l|}{ Puerto Viejo } & 2015-2016 & 2 \\
\hline & & & \multicolumn{2}{|l|}{ Pueblo Nuevo } & $2015-2016$ & 1 \\
\hline & \multirow{12}{*}{ Alajuela } & \multirow{9}{*}{ San Carlos } & \multirow{3}{*}{\multicolumn{2}{|c|}{ La Legua }} & $2015-2016$ & 22 \\
\hline & & & & & 2017-2018 & 10 \\
\hline & & & & & 2019 & 8 \\
\hline & & & & San Luis & $2015-2016$ & 4 \\
\hline & & & & Veracruz & $2015-2016$ & 16 \\
\hline & & & & & $2017-2018$ & 5 \\
\hline & & & \multirow[t]{2}{*}{ Cutris } & Cutris & $2015-2016$ & 8 \\
\hline & & & & San Marcos & $2015-2016$ & 6 \\
\hline & & & Buena Vista & Buena Vista & 2015-2016 & 6 \\
\hline & & \multirow{3}{*}{ Los Chiles } & Los Chiles & Pavón & $2015-2016$ & 12 \\
\hline & & & & & 2016-2017 & 5 \\
\hline & & & & El Carozo & $2015-2016$ & 2 \\
\hline \multirow{7}{*}{ 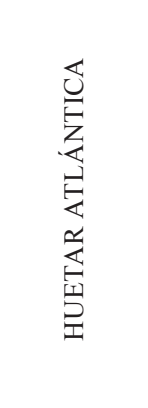 } & \multirow{7}{*}{ Limón } & \multirow{5}{*}{ Pococí } & Cariari & & $2015-2016$ & 4 \\
\hline & & & La Rita & & $2015-2016$ & 5 \\
\hline & & & Guápiles & & $2015-2016$ & 1 \\
\hline & & & Roxana & & 2017-2018 & 7 \\
\hline & & & & & 2019 & 8 \\
\hline & & \multicolumn{3}{|l|}{ Guácimo } & $2015-2016$ & 1 \\
\hline & & \multicolumn{3}{|l|}{ Siquirres } & $2017-2018$ & 7 \\
\hline $\begin{array}{l}\text { PACÍFICO } \\
\text { CENTRAL }\end{array}$ & Puntarena & \multicolumn{3}{|l|}{ Sardinal } & $2017-2018$ & 7 \\
\hline \multirow[t]{5}{*}{ BRUNCA } & San José & Pérez Zeledón & San Pedro & & $2017-2018$ & 8 \\
\hline & SUBTOTAL & & & & $2015-2016$ & 149 \\
\hline & & & & & $2017-2018$ & 50 \\
\hline & & & & & 2019 & 16 \\
\hline & TOTAL & & & & \multicolumn{2}{|c|}{215} \\
\hline
\end{tabular}


La recolección de material se hizo con la colaboración del personal del Servicio Fitosanitario del Estados (SFE) del Ministerio de Agricultura y Ganadería de Costa Rica. Esta consistió en la visita de fincas de piña de las regiones anteriormente nombradas y la recolección de únicamente plantas sintomáticas ubicadas en parches que presentaban síntomas característicos de la enfermedad "muerte descendente del cultivo de piña". Cada planta y fruto fue transportado en sacos sin exceder 24 horas después de extraídas del campo. Las plantas tenían intactas las siguientes partes: raíz, tallo, hojas y fruto, en los casos en que estaba presente.

Caracterización de síntomas, aislamiento e identificación de agente causal. Los síntomas se caracterizaron visualmente, especialmente color, tamaño de la planta, daño interno a nivel de planta y fruto, y el estado de la raíz y se tomaron fotografías de cada síntoma de interés con una cámara Canon SX160IS.

A partir de la zona de avance de los síntomas más evidentes se realizaron cortes de tejido en las plantas (French y Hebert 1980). Cada trozo del tejido se desinfectó con etanol al 70\% e hipoclorito de sodio al $1 \%$ durante 50 y 20 segundos respectivamente y se realizaron 3 lavados con agua estéril. De cada planta se hicieron al menos 4 platos de cultivo, cada uno con 5 segmentos de tejido sintomático. Cada plato contenía medio PDA (agar de dextrosa y papa) (Difco) al 1,5\%, acidificado con ácido láctico $(0,1 \%)$ y conservados a $22^{\circ} \mathrm{C}$ en una cámara de incubación marca Thermo Scientific, por un periodo de 8 días. Los aislamientos con presencia de Fusarium spp. se transfirieron a medio agar-hojas de clavel (CLA por sus siglas en inglés, Carnation Leaf Agar) (Leslie y Summerell 2006) para facilitar el desarrollo de macro y microconidios. El micelio de cada aislamiento fue conservado en discos de papel filtro que se almacenaron a una temperatura de $-80^{\circ} \mathrm{C}$ por tiempo ilimitado.

Para los aislamientos a partir de los frutos, discos de $1,9 \mathrm{~cm}$ de diámetro de la cáscara (zona del tercio inferior), y de la zona del corte del pedúnculo se colocaron en $40 \mathrm{ml}$ de agua destilada con una gota del dispersante Tween 80 . Se colocaron en agitación por 5 minutos, se realizó una dilución de la suspensión $(0,1 \mathrm{ml}$ de la muestra se combinó con $0,9 \mathrm{ml}$ de agua destilada estéril), se agitó nuevamente para luego tomar una alícuota de $0,1 \mathrm{ml}$ y con ayuda de un asa Drigalski se distribuyó sobre una placa de Petri con medio PDA acidificado. Tres repeticiones de cada muestra se colocaron en incubación a $22^{\circ} \mathrm{C}$. Posteriormente, se reaislaron para obtener aislamientos más puros.

Se verificó la apariencia y coloración del micelio mediante la observación en un estereoscopio Motic SMZ-168 (Hong Kong, China). Los aislamientos encontrados en mayor frecuencia se les realizó la identificación molecular.

Posteriormente y por medio del microscopio de luz, Olympus modelo BX41BF (Tokio, Japón) con un lente de aumento de 40X, se describieron los caracteres morfológicos para cada uno de los cultivos axénicos de Fusarium spp. de acuerdo con su identificación por medios moleculares. Se tomó en cuenta el tamaño y la forma de los macroconidios así como el tamaño, la presencia o la ausencia de microconidios, la formación de clamidosporas y la forma de las estructuras de los conidióforos (Summerell et al. 2003, Leslie y Summerell 2006, Summerell 2019).

Para preparar aislamientos puros para los procesos moleculares, se colocó un trozo pequeño de micelio de aproximadamente $5 \mathrm{~mm}^{2}$ en platos con medio de cultivo PDA. También se implementó la metodología a partir de una sola espora, una punta de hifa o la limpieza de los aislamientos con aplicación de antibióticos.

Extracción de ADN, PCR y electroforesis. El análisis molecular se llevó a cabo en el Laboratorio de Técnicas Moleculares aplicadas a la Fitoprotección del CIPROC. Se extrajo ADN a partir de micelio fresco de aislamientos monospóricos y/o puros del hongo, con el método CTAB (Murray y Thompson 1985). Este se cuantificó mediante el espectofotómetro 
BioPhotometer Plus 6132 (Eppendorf, Hamburgo, Alemania) y se llevó a una concentración final de 80 ng.uL ${ }^{-1}$. La amplificación del ADN se llevó a cabo con los marcadores moleculares para la región del ITS del ADN ribosomal: ITS4 (5'- TCCTCCGCTTATTGATATGC-3') y el ITS5 (5' GGAAGTAAAAGTCGTAACAAGG-3') descritos por White et al. (1990) $y$ el factor de elongación alfa (TEF-1 $\alpha$ ): EF1 (5'-ATGGGTAAGGA(A/G)GACAAGAC-3') y EF2 (5'-GGA(G/A)GTACCAGT(G/CATCATGTT-3') para la identificación y caracterización específica de especies de Fusarium (O’Donnell et al. 1998, Geiser et al. 2004).

La reacción de amplificación y el perfil térmico se realizaron por medio de un estándar (Blanco-Meneses y Ristaino 2011). Los productos de amplificación se separaron en un gel de agarosa al $0,8 \%$ con GelRed (Biotium) a 0,5 $\mu \mathrm{g} \cdot \mathrm{mL}^{-1}$ para la tinción y buffer TBE $0.5 \%$, y se compararon con un marcador de peso molecular de 100bp (Thermo Scientific). La presencia de bandas se visualizó con luz ultravioleta.

Secuenciación e identificación de los aislamientos. Un total de 120 productos de PCR se purificaron con la enzima Exonuclease I (Fermentas, Massachusetts, USA) y se llevaron a una concentración de $50 \mathrm{ng} \mu \mathrm{L}-1$. Se utilizó secuenciación de Sanger (Sanger et al. 1977) en la empresa Macrogen Inc., Corea del Sur. La calidad de las secuencias se confirmó con un alineamiento bidireccional y por comparación con los cromatogramas mediante el programa BioEdit Sequence Alignment Editor Versión 7.0.5.3 (Hall 1999). La hebra consenso se utilizó para verificar la similitud en buscadores como Nucleotide Blast del Gen Bank (Clark et al. 2016), EPPO-Q-bank y MycoBank, entre otros, con el empleo de la colección de nucleótidos y la opción de "material tipo" de ser posible (Federhen 2015).

\section{RESULTADOS}

Recolección y caracterización del material. El presente estudio tuvo una duración de 5 años, en los cuales se recolectó un total de 215 muestras en diferentes regiones de Costa Rica. Se recolectó 149 plantas y 20 frutos entre 2015 2016, 50 plantas entre el 2017-2018 y 16 plantas en el 2019 (Tabla 1). Según datos del Servicio Fitosanitario del Estado se cubrió un total de 38175 ha (95\%) del área sembrada de piña, que comprendían 4 provincias, 6 cantones y 18 distritos del país. Se realizó un muestreo dirigido para encontrar parches sintomáticos y relacionados a los síntomas de "muerte descendente del cultivo de piña".

La recolección de plantas enfermas a nivel de campo, se centró en síntomas ligados a desecamiento de las hojas, pérdida de vigor de la plantación y lesiones severas a nivel vascular, específicamente en el tallo, distribuidas en forma de parches de unas cuantas plantas y en otros casos en bloques completos de siembra. El síntoma más característico fue una muerte descendente de las plantas infectadas, las cuales presentaron un amarillamiento, observándose un desecamiento de las hojas de la parte superior (ápice) hacia la base. Cuando la enfermedad estaba avanzada, se presentó un desecamiento total o necrosis en los primeros $15 \mathrm{~cm}$ de las hojas intermedias seguido de pérdida de coloración y turgencia en el resto de las hojas. Del material, se obtuvieron un total de 275 fotos de los síntomas de interés, agrupadas por año, procedencia, descripción de síntomas y resultados de los análisis realizados.

Cada una de las plantas y frutos se analizaron en los laboratorios. La mayoría de las plantas presentaban decoloración amarillenta en las hojas (Figura 1a). Al cortar el tallo longitudinal y transversalmente, se encontró que algunos de los haces vasculares tenían una coloración café de tipo necrótica (Figura 1b y c). En estados avanzados se observó un daño que alcanzaba la mayoría del tallo, además de un tejido translúcido y acuoso pero duro al tacto (Figura 1d y e). El desarrollo radical observado en las muestras analizadas, fue normal en la mayoría de los casos, sin embargo, ocurría descortezamiento de 
las raíces en general (Figura 1f). En un 10\% de las muestras de fruto no se observaron síntomas (Figura 1g), mientras que en el resto, fueron leves incluso la necrosis y corchosis en los alrededores de algunos frutículos. Los síntomas severos se manifestaron como una apariencia bronceada del fruto, restos florales secos y corchosis en frutículos.
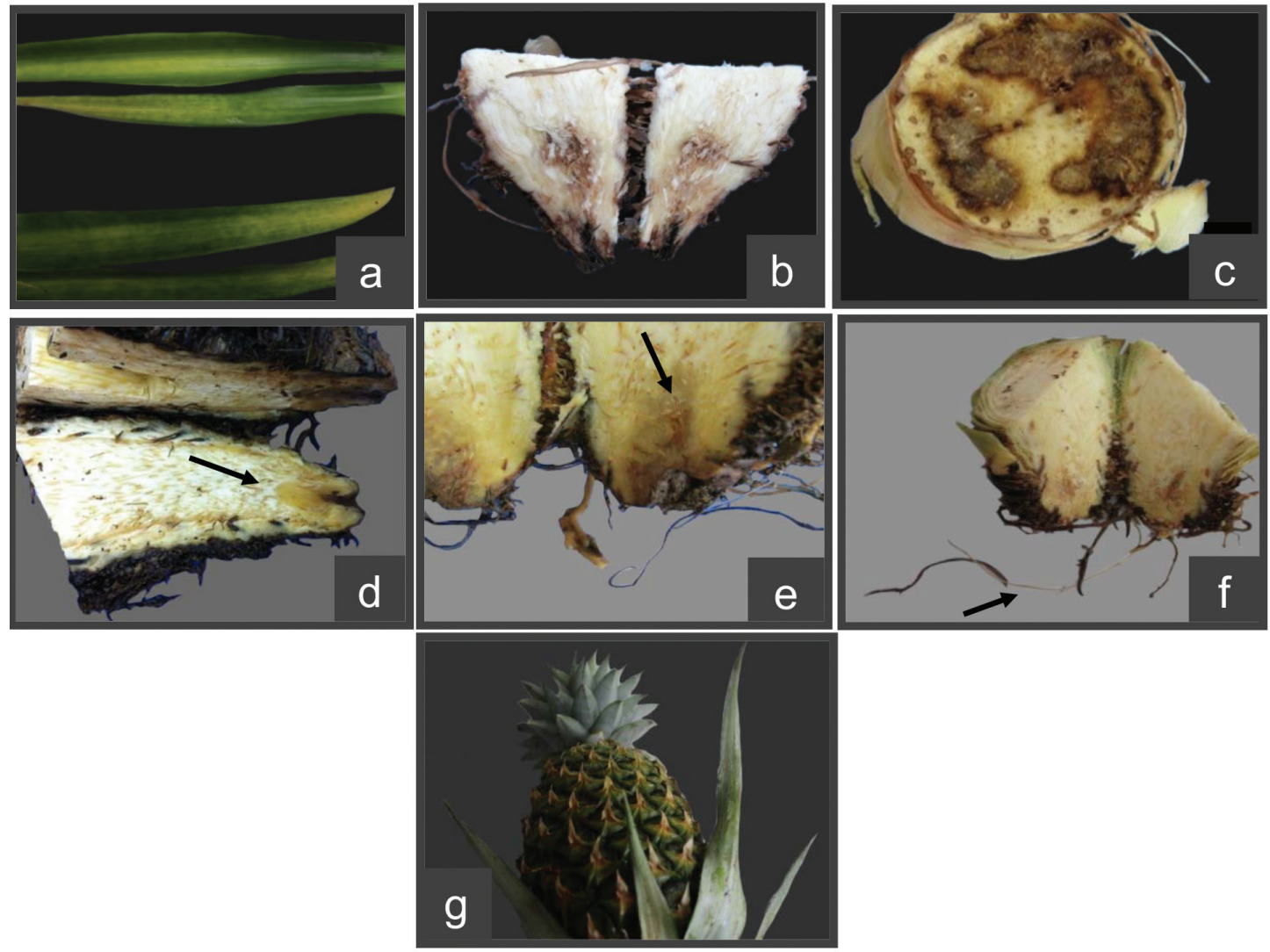

Figura 1. Síntomas asociados a la presencia de Fusarium spp. en plantas de piña. a) amarillamiento en hojas, b) necrosis en tallos al cortar longitudinalmente, c) necrosis en tallo al cortar transversalmente, d y e) tejido translúcido y acuoso, f) raíces con descortezamiento general, g) frutos asintomáticos. Costa Rica 2015-2019.

Posterior a la identificación de los síntomas, se obtuvo un total de 608 platos de cultivo con porciones de tejido provenientes de síntomas relacionados a Fusarium spp. Se agruparon y luego se seleccionaron aquellos que por color y forma del micelio estaban en mayor frecuencia; posteriormente para favorecer la calidad y pure$\mathrm{za}$, se reaislaron un total de 160 aislamientos en medios CLA y en PDA.
Durante 2015-2016 se obtuvo un total de 149 plantas de piña y 20 frutos provenientes de campo. Se analizó un total de 394 platos de cultivo con porciones de tejido provenientes de la base del tallo, raíces internas y externas, follaje, hijos; y del fruto, la cáscara y el pedúnculo. De los aislamientos realizados a partir del tejido de plantas y frutos, en un $63 \%$ creció al menos una especie relacionada al género 
Fusarium, en el $37 \%$ restante se obtuvo en su mayoría bacterias y algunos pocos aislamientos relacionados a otros hongos. De los aislamientos recuperados del fruto, un $95 \%$ correspondieron con Fusarium spp.

En 2017-2018 se volvió a recolectar material de un total de 50 plantas para las cuales se realizó un total de 150 platos de cultivo, cada uno con 5 porciones de tejido provenientes de diferentes partes de tejido sintomático. En un 31\% no hubo crecimiento de microorganismos, en un $27 \%$ creció Pythium spp. o Phytophthora spp., en un $24 \%$ se observó Fusarium y en un $18 \%$ hubo únicamente crecimiento de bacterias.

En el 2019, a partir de 16 plantas recolectadas se realizaron aislamientos en un total de 64 platos de cultivo. Se obtuvo un total de $55,5 \%$ del total de los aislamientos relacionados a especies Fusarium y en un $11,2 \%$ solo hubo crecimiento de bacterias o no hubo crecimiento de microorganismos.

Caracterización molecular de los hongos encontrados en piña. A partir de las 2 regiones genéticas analizadas, se encontró que la región ITS no permitía diferenciar entre las especies de $F$. guttiforme y $F$. ananatum, lo cual inicialmente constituía el objetivo principal de la investigación. Se utilizó para la identificación el factor de elongación 1 alpha que permitió diferenciar entre especies del género Fusarium. A partir de aislamientos monospóricos o puros se identificaron 6 especies de Fusarium en el material aislado a partir de partes de la planta y fruto del cultivo de piña, $F$. ananatum, $F$. oxysporum, $F$. polyphialidicum conocido actualmente como $F$. concolor (nombre que se utilizará para efectos de este artículo), $F$. proliferatum, $F$. incarnatum y F. solani.

Para la identificación, se compararon las secuencias con similares reportadas en GenBank y relacionadas a artículos científicos del cultivo de piña, en otros casos a la secuencia más cercana. Se ingresó en el NCBI, Bankit una secuencia de cada especie para su clasificación y se les asignó un número de accesión (Tabla 2). 


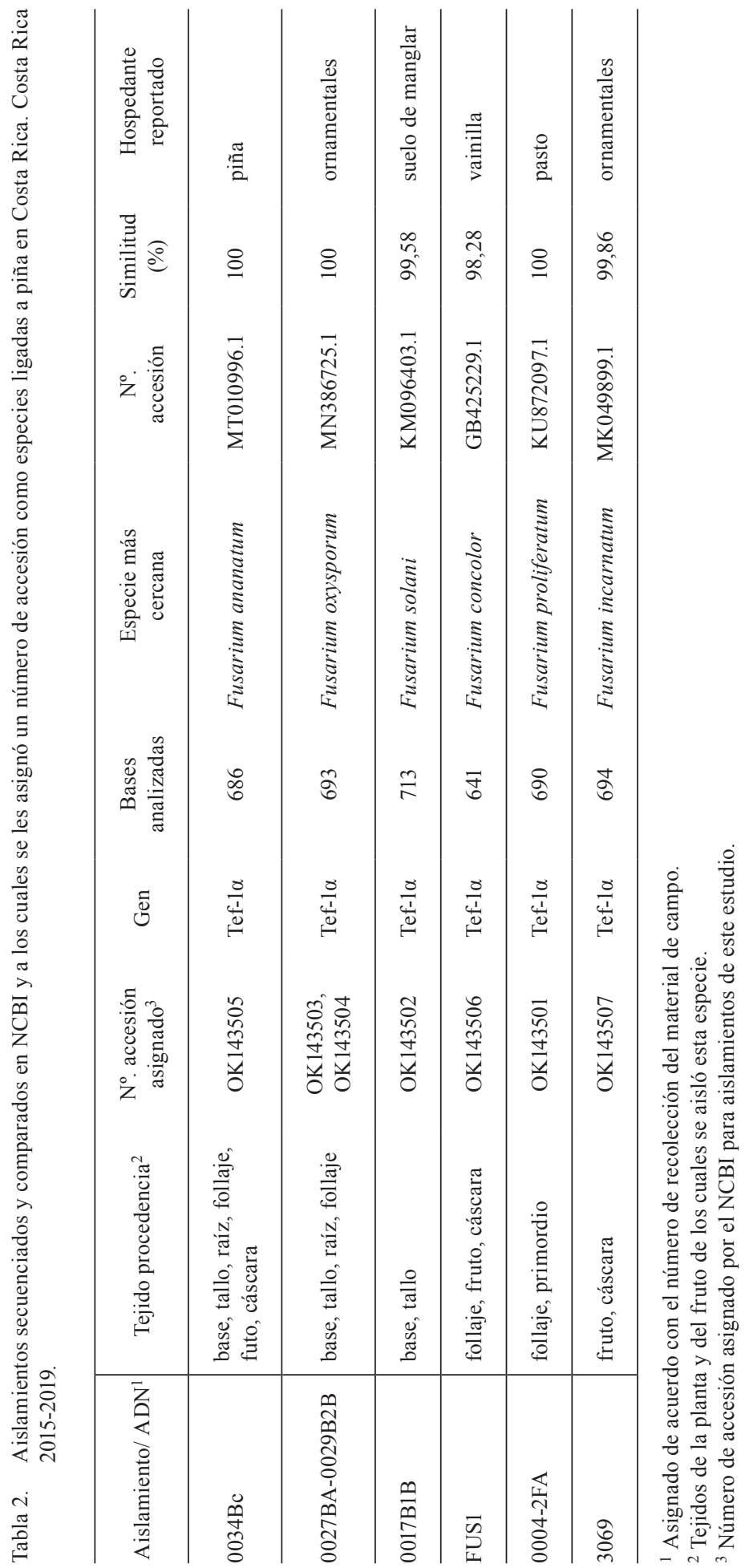


Durante 2015-2016 se identificó un 1,16\% de aislamientos de las especies $F$. solani, $F$. incarnatum y $F$. proliferatum, $6,9 \%$ de aislamientos de $F$. concolor, $13,8 \%$ de aislamientos de $F$. oxysporum y $71,6 \%$ de aislamientos de $F$. ananatum. Del total de los 116 aislamientos, 19 provenían del fruto de la piña y 18 de los mismos se identificaron como $F$. ananatum.

En 2017-2018 en el material que se secuenció relacionado a Fusarium, un $22 \%$ fue $F$. oxysporum y un $2 \%$ correspondió con $F$. ananatum.

En el 2019 los resultados correspondieron a un $55,5 \%$ del total de los aislamientos de $F$. ananatum, un $22,2 \%$ de $F$. oxysporum y en un $11,1 \%$ de $F$. solani.

Caracterización morfológica de los hongos encontrados en piña. Una vez identificadas por medios moleculares las 3 especies patogénicas más frecuentes dentro del género Fusarium de acuerdo con los postulados de Koch (Díaz 2018), fueron descritas morfológicamente con algunas características macroscópicas y microscópicas propias para clasificar el género (Tabla 3). 


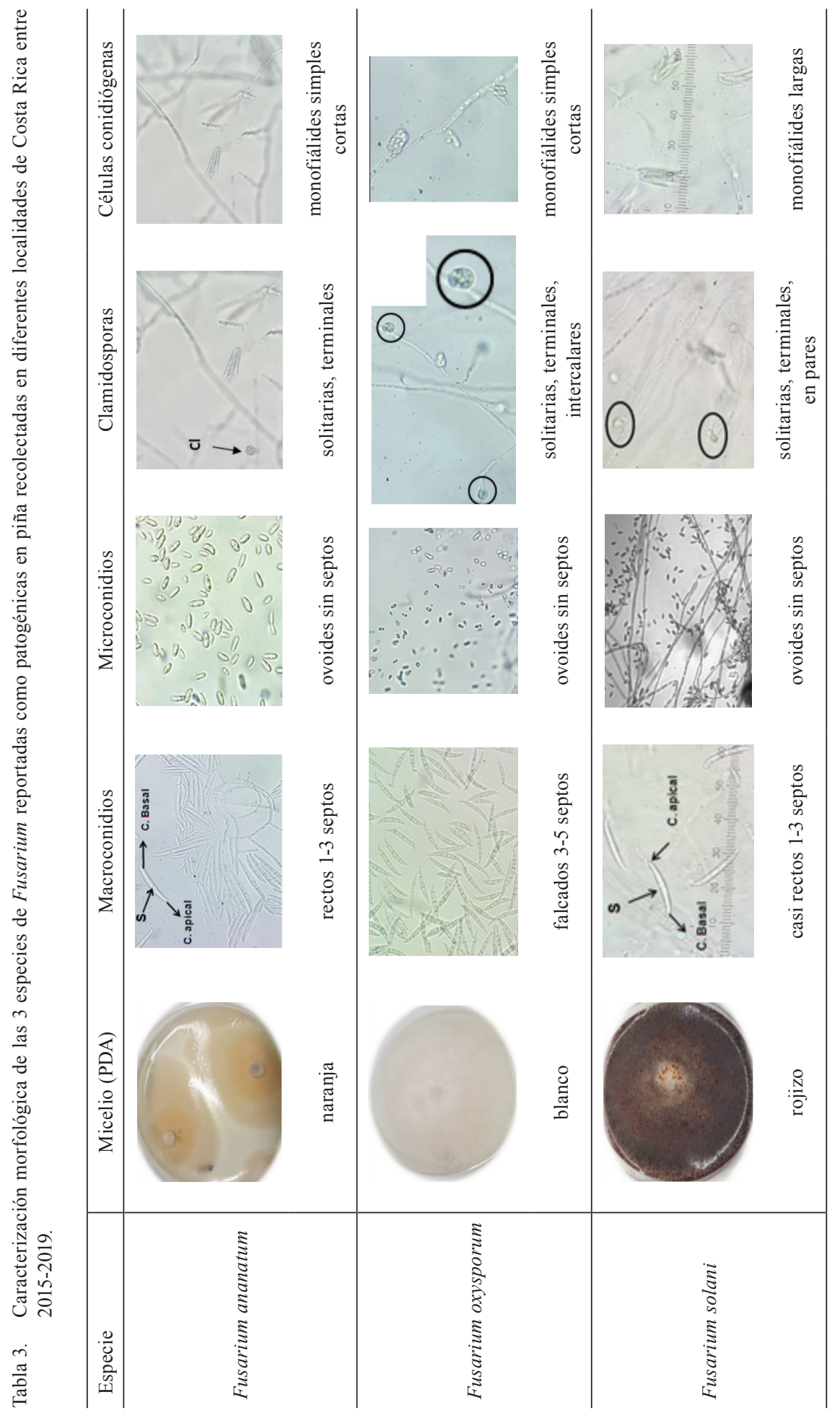


Las colonias correspondientes a $F$. ananatum en medio PDA, presentaban un color que varió entre naranja (ladrillo) a tonos rosados, con anillos concéntricos y un crecimiento aéreo leve en el centro de la misma. Los macroconidios eran cortos con 1 a 3 septos, relativamente rectos (sin curvaturas), con una célula apical aguda y una célula basal redondeada; los microconidios ovoides sin septos. Estos conidios se presentaban unidos a los conidióforos en forma de falsas cabezas. Las células conidiógenas se observaron como monofiálides simples cortas, con escasas clamidosporas solitarias terminales $(\mathrm{Cl})$ (Tabla 3).

En el caso de $F$. oxysporum la coloración del micelio fue blanca o lila en el medio de cultivo PDA. Los macroconidios falcados con 3 a 5 septos, con una célula apical aguda y una célula basal en forma de pie y los microconidios ovoides sin septos. Las clamidosporas abundantes y se encontraron de forma solitaria, terminales e intercalares. Las células conidiógenas se mostraron como monofiálides simples cortas (Tabla 3).

F. solani desarrolló una coloración rojiza en el micelio aéreo al crecer en el medio de cultivo PDA. Los macroconidios eran angostos, casi rectos con 3 a 7 septos, con una célula apical aguda y una célula basal en forma de pie. Las células conidiógenas se observaron como monofiálides largas y las clamidosporas terminales, solitarias y en pares (Tabla 3).

En varios aislamientos fue posible observar la presencia de dos especies de Fusarium que convivían en la misma lesión.

\section{DISCUSIÓN Y CONCLUSIONES}

El cultivo de piña en Costa Rica es importante a nivel económico para el ingreso de divisas y como actividad que provee trabajo a un alto porcentaje de la población del país, sin embargo, la aparición de enfermedades dificulta el manejo del cultivo e incrementa los costos de producción. El objetivo principal de esta investigación fue verificar la presencia o ausencia del patógeno $F$. guttiforme en plantaciones de piña ubicadas en
Costa Rica y las especies presentes en el cultivo. Primero, se logró determinar la ausencia en el país de F. guttiforme por medio de técnicas moleculares. Segundo, se pudo identificar la presencia de 6 especies de Fusarium relacionadas al cultivo de piña, algunas especies reportadas como patogénicas en este y otros cultivos. Finalmente, las especies encontradas fueron caracterizadas a nivel morfológico y molecular, a partir de los aislamientos generados.

A partir de porciones de tejido provenientes de plantas sintomáticas relacionadas a "la muerte descendente en piña" se identificaron 6 especies: Fusarium ananatum, $F$. oxysporum, $F$. solani, $F$. incarnatum, $F$. concolor y $F$. proliferatum. Además de la presencia de Fusarium se pudo identificar la presencia de otros patógenos como Pythium spp. o Phytophthora spp., y múltiples microorganismos como Penicillium spp., Cladosporium spp., bacterias y levaduras. Esto permite concluir que dentro de cualquier planta o cultivo existe una serie de microorganismos que interactúan durante el desarrollo del mismo; algunos organismos endógenos que se relacionan con la planta sin causar aparente sintomatología y otros previamente reportados como patógenos que podrían ocasionar síntomas, bajo las condiciones adecuadas (Castro y Umaña 2017, Fritiani et al. 2020).

En este estudio no fue posible diferenciar las 6 especies con base en la sintomatología que se observó en las plantas, ya que era común encontrar el mismo tipo de daño. La presencia de las diferentes especies podría ligarse a condiciones climáticas favorables para el desarrollo del patógeno, a la diversidad de cultivos presentes en las zonas previo a la siembra del cultivo de piña, y no se descarta factores como prácticas y tecnologías utilizadas para el manejo del cultivo.

En el fruto, se identificó la presencia de $F$. ananatum en un $95 \%$ de los aislamientos realizados a partir de porciones de la cáscara del fruto y el corte del pedúnculo provenientes de plantas enfermas, aunque en algunas ocasiones sin síntomas visibles. Debido a que el fruto es el producto comercializado para este cultivo es 
necesario realizar más estudios sobre el daño que podría ocasionar este patógeno. En este estudio, se reporta que la especie $F$. ananatum es el agente causal de la pudrición del centro del frutículo, PCF (fruitlet core rot, FCR) en plantas de piña de Costa Rica, encontrándose el hongo no solo en el fruto sino en aislamientos provenientes de hojas, tallo y raíz.

F. ananatum causa un daño interno, considerándose aproximadamente 12 días lo requerido, luego de la llegada del inóculo a la planta, para causar las mayores lesiones en el fruto (Barral et al. 2017), sin embargo, el mismo no se logra apreciar desde la parte externa del fruto. A pesar de que se reporta la dispersión de este patógeno por medio de esporas de forma aérea, durante la maduración del fruto, Jacobs et al. 2010 afirman que este no cuenta con toxinas que le permitan entrar y degradar las partes externas, más gruesas, del fruto de piña. En investigaciones posteriores, se encontró que la infección ocurre durante el desarrollo de la inflorescencia, el patógeno permanece latente por un tiempo y durante la maduración del fruto, y así $F$. ananatum inicia con el desarrollo de los síntomas (Barral et al. 2017), lo que se ve favorecido por temperaturas medias y una alta humedad en el ambiente (Fournier et al. 2015). Conforme el fruto alcanza la maduración, los síntomas de necrosis en las brácteas del fruto aumentan e incluso pueden darse síntomas de corchosis o formación de manchas "bolsillo de cuero" (Rohrbach et al. 2003), en otros casos la presencia de este patógeno se ha asociado a la permanencia del fruto en un estado verde y que no se torna amarillo con la maduración, lo cual se ha denominado "fruto verde" (Pires de Matos 2019). Usualmente los síntomas no son visibles a nivel externo en el fruto, esto hace que esta enfermedad sea más difícil de detectar por parte de los productores y los consumidores de piña. La agresividad de $F$. ananatum también depende de la variedad de piña utilizada, cultivares como "Queen" se consideran altamente susceptibles, el "Smooth Cayenne" es considerado moderadamente susceptible, mientras que en el "MD2", es menos frecuente al desarrollo de los síntomas en el tejido, aunque el patógeno esté presente. En Costa Rica la variedad MD2 es la de mayor producción. Barral et al. 2019 relacionan esta resistencia directamente a la estructura floral donde el tejido es más compacto en cultivares como MD2, mientras que en variedades como Queen existen muchos espacios libres que permiten el crecimiento de estructuras del hongo. A la vez, la aparición de paredes lignificadas por la producción de ácidos fenólicos en altas cantidades funciona como un mecanismo de defensa preventivo para la colonización del hongo (Barral et al. 2019, Barral et al. 2020).

La infección en plantas de piña con $F$. ananatum se ha asociado a la presencia del vector Steneotarsonemus ananas. Este infecta las flores abiertas aunque también logra penetrar a través del tejido del fruto por la presencia de heridas (Pires de Matos 2019). Este ácaro ya fue descrito en Costa Rica en el 2012 por Aguilar y Murillo. La presencia de un vector hace aún más difícil el manejo de la PCF y es necesario el uso de pesticidas para reducir las poblaciones del ácaro. Esto representa agregar más químicos, en un cultivo como la piña, en el cual la aplicación de agroquímicos y fertilizantes es intensiva. La investigación para encontrar posibles controladores biológicos del ácaro sería un tema prioritario a considerar.

Jacobs et al. 2010 describen los aislamientos de $F$. ananatum localizados en Sur África como una nueva especie de Fusarium y se diferencia de otras especies por sus secuencias de ADN mediante las regiones de la Histona H3, de la $\beta$-tubulina (BT), de los genes del factor de elongación $1 \alpha$ (TEF) y también de acuerdo con sus características morfológicas. En los aislamientos provenientes de Costa Rica, la morfología lo define con presencia de conidióforos de naturaleza erecta en el micelio aéreo y la distribución de micelio aéreo en la superficie de los aislamientos, especialmente en el centro del aislamiento. A la vez, se pueden observar círculos concéntricos de crecimiento de micelio y un 
característico color "ladrillo" de las colonias en medio PDA. En el fruto los síntomas asociados tanto a $F$. guttiforme y a $F$. ananatum son muy similares, pero son menos severos en el último de los 2 hongos. En $F$. guttiforme se da una decoloración en el fruto, sin embargo, en la parte infectada se observa una lesión en forma de $\mathrm{V}$ (uve) que al inicio no tiene color, pero luego se torna acuosa (Jacobs et al. 2010). A pesar de que $F$. ananatum parece tener una aparente menor agresividad es un organismo que está presente en Costa Rica y al cual hay que darle un seguimiento cercano.

El segundo organismo más común en este estudio fue $F$. oxysporum f. sp. ananas, que ha sido el patógeno reportado como causante del daño en plantas de piña en Costa Rica en años anteriores. Este, se caracteriza por una muerte regresiva en la planta, desecamiento de las hojas, notable pérdida de vigor de la plantación y severas lesiones a nivel vascular, específicamente en el tallo (Rojas 2020, Vázquez y Mata 2014, Vásquez-Jiménez 2009). En Brasil esta especie actúa simultáneamente con $F$. ananatum y $F$. guttiforme. Su ingreso se da por la raíz y puede mantenerse en suelo por largos períodos de tiempo. También se ha reportado en la variedad Cayena Lisa en Perú y se ha relacionado a clorosis, enrojecimiento progresivo de las hojas basales hacia las hojas superiores, muerte regresiva de la planta, encarrujamiento de puntas y necrosis, frutos pequeños atrofiados, cloróticos y volcamiento de los frutos por encorchamiento de los pedúnculos (Rojas 2020). Esta ha sido caracterizada tanto a nivel morfológico como molecular en varios estudios (Rojas 2020, Vázquez y Mata 2014, Vásquez-Jiménez 2009).

$F$. proliferatum fue recuperado e identificado como causante del moho en el corte del pedúnculo de piña, y se ha encontrado en el análisis de otras muestras de frutos de piña, así como en diferentes fases del proceso poscosecha (Castro y Umaña 2015, Castro y Umaña 2017). Además, se le ha relacionado a patologías observadas en Malasia con pudrición de fruto y de tejidos de la planta (Ibrahim et al. 2017, Ibrahim et al. 2020). La habilidad de este patógeno de producir micotoxinas ha sido analizada mediante el gen FUM1, que actúa como indicador de la presencia de la fumonisina $\mathrm{B}_{1}\left(\mathrm{FB}_{1}\right)$ así como por medio de cromatografía donde se estudió la presencia de moniliformina (MON) y beauvericina (BEA). Este patógeno es capaz de producir fumonicinas, las cuales junto con tricoticenos y zearalenona, son de las micotoxinas más peligrosas para la salud animal y humana (Barral et al. 2020, Ibrahim et al. 2020).

Estudios en el fruto han indicado la presencia de micotoxinas además de un incremento en la producción de fenoles, ácidos coumaroylisocitrico y cafeoyl-isocitrico ante la presencia de especies de Fusarium. Se ha encontrado concentraciones altas de micotoxinas ante la inoculación con $F$. ananatum y $F$. proliferatum al comparar con frutos no inoculados, especialmente las fumonisinas B1 y B2. Además, se encontró que $F$. oxysporum es capaz de producir beauvericina (Barral et al. 2017, Barral et al. 2020). Esto podría representar un riesgo para la salud humana a la hora se ser consumido el fruto, por lo que se recomienda realizar un estudio más exhaustivo al respecto.

Otras especies como $F$. concolor, F. incarnatum y $F$. solani no han sido descritas como patógenos de piña hasta el momento.

Con este estudio se pudo constatar que el patógeno $F$. guttiforme aun no está presente en el cultivo de piña en Costa Rica, además se logró identificar las especies de Fusarium que interactuaban en el cultivo de la piña. En este trabajo se presenta un estudio preliminar que sugiere investigación más profunda en aspectos como: la interacción del cultivo de piña con otras especies patogénicas y no patogénicas, la presencia de especies productoras de micotoxinas, la interacción de Fusarium y vectores transmisores de enfermedades y el efecto de la PCF en las variedades de piña cultivadas en el país, entre otros. Esto llevará a establecer un mejor manejo del cultivo y favorecer prácticas que mejoren la calidad de la fruta y por ende un consumo más sano. 


\section{AGRADECIMIENTO}

Un especial agradecimiento al personal del Servicio Fitosanitario del Estado, MAG, por la recolección de material. A los productores de piña por facilitar la toma de las muestras de plantas sintomáticas para los análisis morfológicos y moleculares. A la Vicerrectoría de Investigación de la Universidad de Costa Rica por facilitar esta investigación como parte del proyecto 813-B4-230.

\section{LITERATURA CITADA}

Aguilar, H; Murillo, P. 2012. Nuevos hospederos y registros de ácaros fitopatógenos para Costa Rica: Período 2008-2012. Agronomía Costarricense 36(2):11-28.

Aoki, T; O’Donnell, K; Geiser, D. 2014. Systematics of key phytopathogenic Fusarium species: current status and future challenges. Journal of General Plant Pathology 80:189-201. DOI: https://doi.org/10.1007/ s10327-014-0509-3.

Avendaño, M. 2019. Clima y exceso de oferta golpean fuerte a cultivos de exportación (en línea). San José, Costa Rica, ElFinanciero. Consultadoago. 2021. Disponible en https://www.pressreader.com/costa-rica/ el-financiero-costa-rica/20190713/281754155895459

Barral, B; Chillet, M; Doizy, A; Grassi, M; Ragot, L; Lechaudel, M; Durand, N; Rose, L; Viljoen, A; Schorr-Galindo, S. 2020. Diversity and Toxigenicity of Fungi that Cause Pineapple Fruitlet Core Rot. Toxins 12:339. DOI: https://doi.org/10.3390/ toxins 12050339 .

Barral, B; Chillet, M; Lechaudel, M; Lartaud, M; Verdeil, JL; Conejero, G; Schorr-Galindo, S. 2019. An Imaging Approach to Identify Mechanisms of Resistance to Pineapple Fruitlet Core Rot. Frontiers in Plant Science 10:1065. DOI: https://doi.org/10.3389/ fpls.2019.01065.

Barral, B; Chillet, M; Minier, J; Lechaudel, M; SchorrGalindo, S. 2017. Evaluating the response to Fusarium ananatum inoculation and antifungal activity of phenolic acids in pineapple. Fungal Biology 121:1045-1053. DOI: https://doi. org/10.1016/j.funbio.2017.09.002.

Blanco-Meneses, M; Ristaino, J. 2011. Detection and quantification of Peronospora tabacina using a Real-time Polymerase Chain Reaction assay. Plant Disease 95(6):673-682. DOI: https://doi.org/10.1094/ PDIS-05-10-0333.

CANAPEP. 2016. Cámara Nacional de Productores y Exportadores de piña (en línea). San José, Costa
Rica. Consultado ago. 2021. Disponible en https:// canapep.com

Castro, J; Umaña, G. 2015. Poblaciones e identificación de los hongos causantes de mohos poscosecha en el pedúnculo de la piña, en dos zonas de Costa Rica. Agronomía Costarricense 39(3):61-77. DOI: https:// doi.org/10.15517/RAC.V39I3.21792.

Castro, J; Umaña, G. 2017. Frecuencia de los hongos asociados al desarrollo de mohos poscosecha en el pedúnculo de la piña en dos zonas de Costa Rica. Agronomía Costarricense 41(2):17-25. DOI: https:/ doi.org/10.15517/RAC.V41I2.31296.

Clark, K; Karsch-Mizrachi, I; Lipman, DJ; Ostell, J; Sayers, EW. 2016. GenBank. Nucleic Acids Research 44(1):67-72. DOI: https://doi.org/10.1093/nar/ gkv1276.

De Farias, GM; Belisario, P; Shaun, D; Ventura, J; Machado, P; Ribeiro, A. 2010. Cell wall alterations in the leaves of fusariosis-resistant and susceptible pineapple cultivars. Plant Cell Reports 29:1109-1117. DOI: https://doi.org/10.1007/s00299-010-0894-9.

Díaz, G. 2018. Patogenicidad de diferentes aislamientos de Fusarium spp. y su efecto sobre la calidad en piña (Ananas comosus) en poscosecha. Tesis Lic. San José, Costa Rica Universidad de Costa Rica. 60 p.

Federhen, S. 2015. Type material in the NCBI Taxonomy Database. Nucleic Acids Research 43(D1):D1086-D1098. DOI: https://doi.org/10.1093/ nar/gku1127.

Fitriani, R; Putrie, W; Aryantha, N; Prayogo, I; Antonius, S. 2020. Diversity of endophytic and rhizosphere bacteria from pineapple (Ananas comosus) plant in semi-arid ecosystem. Biodiversitas Journal of Biological Diversity 21:3084-3093. DOI: http:/ www.doi.org/10.13057/biodiv/d210728.

Fournier, P; Benneveau, A; Hardy, C; Chillet, M; Lechaudel, M. 2015. A predictive model based on a pluviothermic index for leathery pocket and fruitlet core rot of pineapple cv. 'Queen'. European Journal of Plant Pathology 142:449-460. DOI: https://doi. org/10.1007/s10658-015-0625-8.

French, E; Hebert, T. 1980. Métodos de investigación fitopatológica. San José, Costa Rica, Instituto Interamericano de Ciencias Agrícolas IICA. 288 p.

Gamboa, E. 2019. Identificación taxonómica y molecular de especies del nematodo lesionador de la raíz Pratylenchus spp. (Nematoda: Pratylenchidae) asociado a cuatro cultivos de Costa Rica. Tesis Lic. Heredia, Costa Rica, Universidad Nacional. 80 p.

Geiser, DM; Jiménez-Gasco, MM; Kang, S; Makalowska, I; Veeraraghavan, N; Ward, TJ; Zhang, N; Kuldau, GA; O'Donnell, K. 2004. FUSARIUM-ID v. 1.0: A DNA sequence database for identifying Fusarium. European Journal of Plant Pathology 110:473-479. DOI: https://doi.org/10.1023/ B:EJPP.0000032386.75915.a0. 
Gu, H; Zhang R; Zhang, L; Gong, Q; Jia, Z. 2015. First report of Fusarium ananatum causing pineapple fruitlet core rot in China. Chinese Academy of Tropical Agricultural Sciences 99(11):1653. DOI: https://doi.org/10.1094/PDIS-03-15-0279-PDN.

Hall, TA. 1999. BioEdit: A user-friendly biological sequences aligment editor and analysis program for Windows. Nucleic Acids Symposium Series 41:95-98.

Ibrahim, NF; Mohd, MH; Izham, NM; Nor, M; Zakaria, M. 2017. Characterization of Fusarium spp. associated with pineapple fruit rot and leaf spot in Peninsular Malaysia. Journal of Phytopathology 165:718-726. DOI: https://doi.org/10.1111/jph.12611.

Ibrahim, NF; Mohd, MH; Izham, NM; Nor, M; Zakaria, M. 2020. Mycotoxigenic potential of Fusarium species associated with pineapple diseases. Archives of Phytopathology and Plant Protection 53:5-6. DOI: https://doi.org/10.1080/03235408.2020.1736971.

Jacobs, A; Schalk, V; Marasas, O; Wingfield, B; Wingfield, M; Coutinho, T. 2010. Fusarium ananatum sp. in the Gibberella fujikuroi complex from pineapples with fruit rot in South Africa. Fungal Biology 114:515-527. DOI: https://doi.org/10.1016/j.funbio.2010.03.013.

Leslie, JF; Summerell, BA. 2006. The Fusarium Laboratory Manual. Iowa, USA, Wiley-Blackwell. 388 p.

Monge, M. 2018. Guía para la identificación de la principales plagas y enfermedades en el cultivo de piña (en línea). San José, Costa Rica. Consultado ago. 2021. Disponible en http://cica.ucr.ac.cr/wp-content/ uploads/2020/11/Manual-de-plagas-Pi\%C3\%B1aCICA-08-10-20191_compressed.pdf

Murray, MG; Thompson, WF. 1985. Rapid isolation of high molecular weight plant DNA. Nucleid Acids Research 8(19):4321-4325. DOI: https://doi. org/10.1093/nar/8.19.4321.

Nirenberg, HI; O’Donnell, K. 1998. New Fusarium Species and Combinations within the Gibberella fujikuroi Species Complex. Mycologia 90(3):434-458. DOI: https://doi.org/10.2307/3761403.

OIRSA. 2011. Fusariosis de la piña: Fusarium guttiforme. Reglamentación Fitosanitaria para la importación, Normas Regionales en Sanidad Vegetal, Directrices para la protección contra Fusarium guttiforme (en línea). San Salvador, El Salvador. Consultado ago. 2021. Disponible en https://www.oirsa.org/ informacion.aspx?id $=85$

O’Donnell, K; Kistler, HC; Cigelnik, E; Ploetz, R. 1998. Multiple evolutionary origins of the fungus causing Panama disease of banana: concordant evidence from nuclear and mitochondrial gene genealogies. Proceedings of the National Academy of Sciences of the United States of America 95:2044-2049. DOI: https://doi.org/10.1073/pnas.95.5.2044.

O'Donnell, K; Sutton, DA; Rinaldi, MG; Gueidan, C; Crous, PW; Geiser, DM. 2009. Novel multilocus sequence typing scheme reveals high genetic diversity of human pathogenic members of the Fusarium incarnatum- $F$. equiseti and $F$. chlamydosporum species complexes within the United States. Journal of Clinical Microbiology 47(12):3851-3861. DOI: https://doi.org/10.1128/JCM.01616-09.

Pires de Matos, A. 2019. Main pests affecting pineapple plantations and their impact on crop development. Acta Horticulturae 1239:137-146. DOI: https://doi. org/10.17660/ActaHortic.2019.1239.17.

Retana, K; Ramírez-Coché, J; Castro, O; Blanco-Meneses, M. 2018. Caracterización morfológica y molecular de Fusarium oxysporum f. sp. apii asociado a la marchitez del apio en Costa Rica. Agronomía Costarricense 42(1):115-126. DOI: http://dx.doi. org/10.15517/rac.v42i1.32199.

Rohrbach, KG; Leal, F; Coppens, G. 2003. The pineapple botany, production and uses. In Bartholomew, D; Paull, R; Rohrbach, K (eds.). History, Distribution and World Production. New York, USA, CAB International. p. 1-10.

Rojas, JE. 2020. Aislamiento, patogenicidad y caracterización molecular de Fusarium oxysporum Schltdl, que afecta piña (Ananas comosus) en Poroto, La Libertad. Tesis M.Sc. Perú, Universidad Nacional de Trujillo. 49 p.

Sanger, F; Nicklen, S; Coulson, AR. 1977. DNA sequencing with chain-terminating inhibitors. Proceedings of the National Academy of Sciences of the United States of America 74(12):5463-5467. DOI: https:// doi.org/10.1073/pnas.74.12.5463.

Secretaría Ejecutiva de Planificación Sectorial Agropecuaria (SEPSA). 2021. Informe Comercio Exterior del Sector Agropecuario 2019-2020 (en línea). San José, Costa Rica. Consultado ago. 2021. Disponible en http://www.sepsa.go.cr/docs/2021-003-Comercio_ Exterior_2019-2020.pdf

Singleton, P; Sainsbury, D. 2006. Fusarium from Dictionary of Microbiology \& Molecular Biology. 3 ed. Chicago, United States, John Wiley \& Sons Ltd. p. 71-93.

Summerell, BA. 2019. Resolving Fusarium: Current Status of the Genus. Annual Review of Phytopathology 57(1):323-339. DOI: https://doi.org/10.1146/annurevphyto-082718-100204.

Summerell, BA; Salleh, B; Leslie, J. 2003. A Utilitariam approach to Fusarium identification. Plant Disease 87(2):117-128. https://doi.org/10.1094/ PDIS.2003.87.2.117.

Ulate, M. 2018. Identificación, patogenicidad y respuesta al metalaxil de aislamientos de Phytophthora spp. de diez fincas piñeras en Costa Rica. Tesis M.Sc. San José, Costa Rica, Universidad de Costa Rica. 96 p.

Vásquez, J; Mata, X. 2014. Diagnosis of Fusarium oxysporum in the cultivation of pineapple Ananas comosus (L) Merr. Net Journal of Agricultural Science 2(3):107-112. 
Vásquez-Jiménez, J. 2009. Evaluación de la eficacia in vitro de sustancias químicas y microorganismos antagónicos del género Trichoderma spp., como herramienta para la toma de decisiones en el control de enfermedades "caso muerte descendente del cultivo de piña Ananas comosus (L) Merr". Tesis Lic. San Carlos, Costa Rica, Instituto Tecnológico de Costa Rica. 75 p.

Ventura, JA; Zambolim, L; Gilbertson, L. 1993. Proposicao de nova forma specialis em Fusarium subglutinans no abacaxizeiro. Fitopatologia Brasileira 18:280.
Vindas, A; Blanco, H. 2013. Control de Dysmicoccus brevipes (Hemiptera: Pseudococcidae), en el fruto de piña, San Carlos, Costa Rica. Agronomía Costarricense 37(1):103-111.

White, TJ; Bruns, T; Lee, S; Taylor, J. 1990. Amplification and direct sequencing of fungal ribosomal RNA genes for phylogenetics. In Innis, DH; Gelfand, JJ; Sninsky, TJ (eds.). PCR Protocols: A guide to Methods and Applications. San Diego, USA, Editorial M. A. White Academic Press. p. 315-322. 